\title{
A Survey on Completed Suicides by Poisoning Encountered in an Emergency Room of a University Hospital in Japan
}

OMasato MASUDA, Nobuaki ETO, Mayuko MATSUO, Kohei HARADA, Leo GOTOH, Yuka TANAKA, Kentaro KIRA, Yuma OGUSHI, Akito HATANAKA, Hiroaki KAWASAKI E-mail : m.masuda.med@gmail.com (Masato MASUDA)

Fukuoka University, Department of Psychiatry, Faculty of Medicine, Fukuoka-City, Japan

We found 16 cases of completed suicides by poisoning in 12 years, and $75 \%$ of them had a history of psychiatric care, which emphasizes the importance of psychiatric care for preventing suicide in the future.

\section{Background}

Suicide attempt by poisoning is common worldwide, though fatality rate is not so high. Our study is to give data of all fatal cases in an Emergency Room (ER) of Fukuoka University hospital.

\section{Methods}

We analyzed all fatal cases, during April 2006 to March 2018, and their demographic information, poisonous agents employed, subsequent hospitalization, psychiatric assessment and treatment.

\section{Results}

\section{3-1) Demographic Information}

There were 16 completed suicides by poisoning (female $\mathrm{n}=8$, average age 41.2).

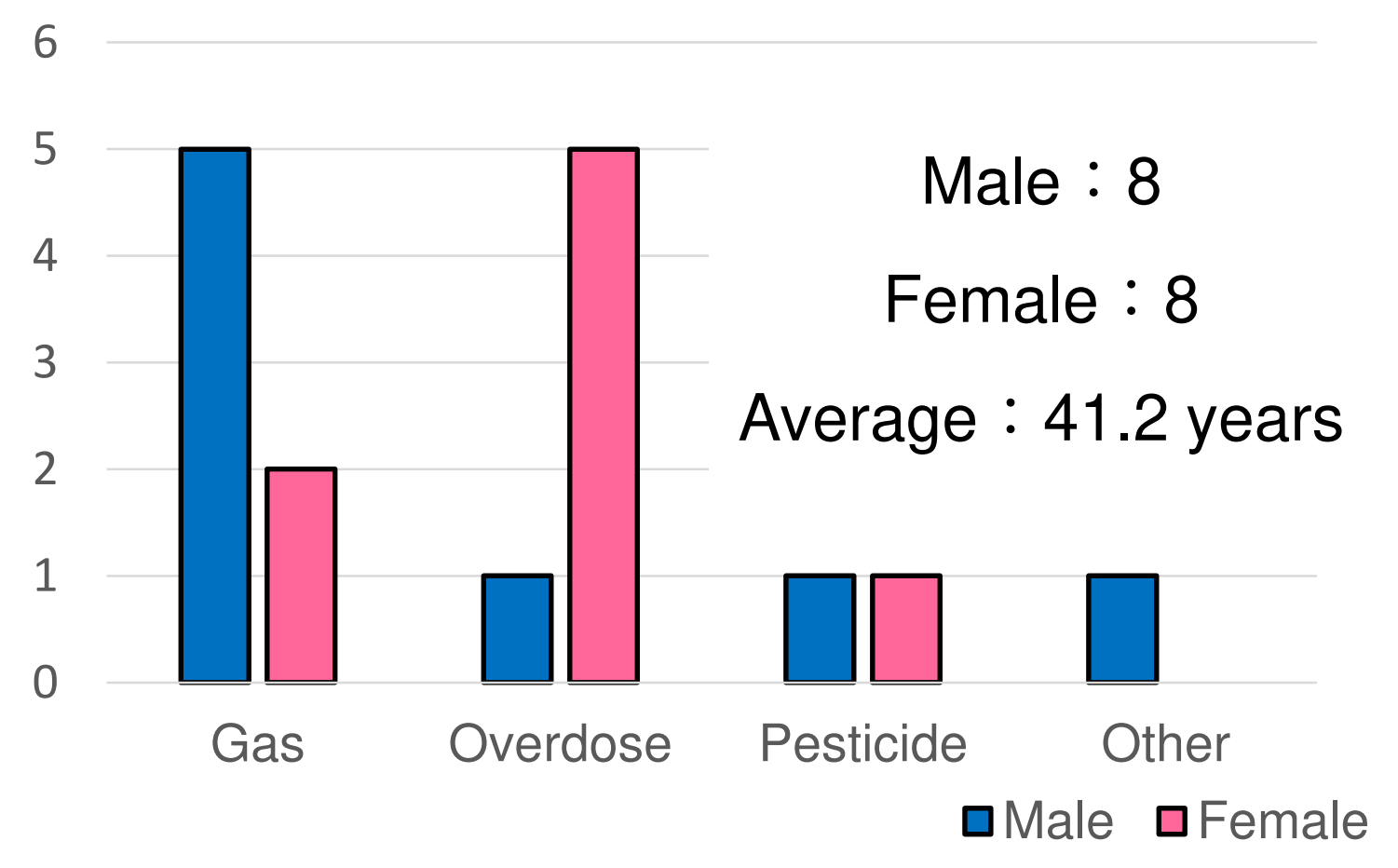

\section{3-2) Poisonous Agents Employed}

Agents used included 7 gases, 5 overdoses, 2 agricultural pesticides, 1 stimulant, and 1 detergent.

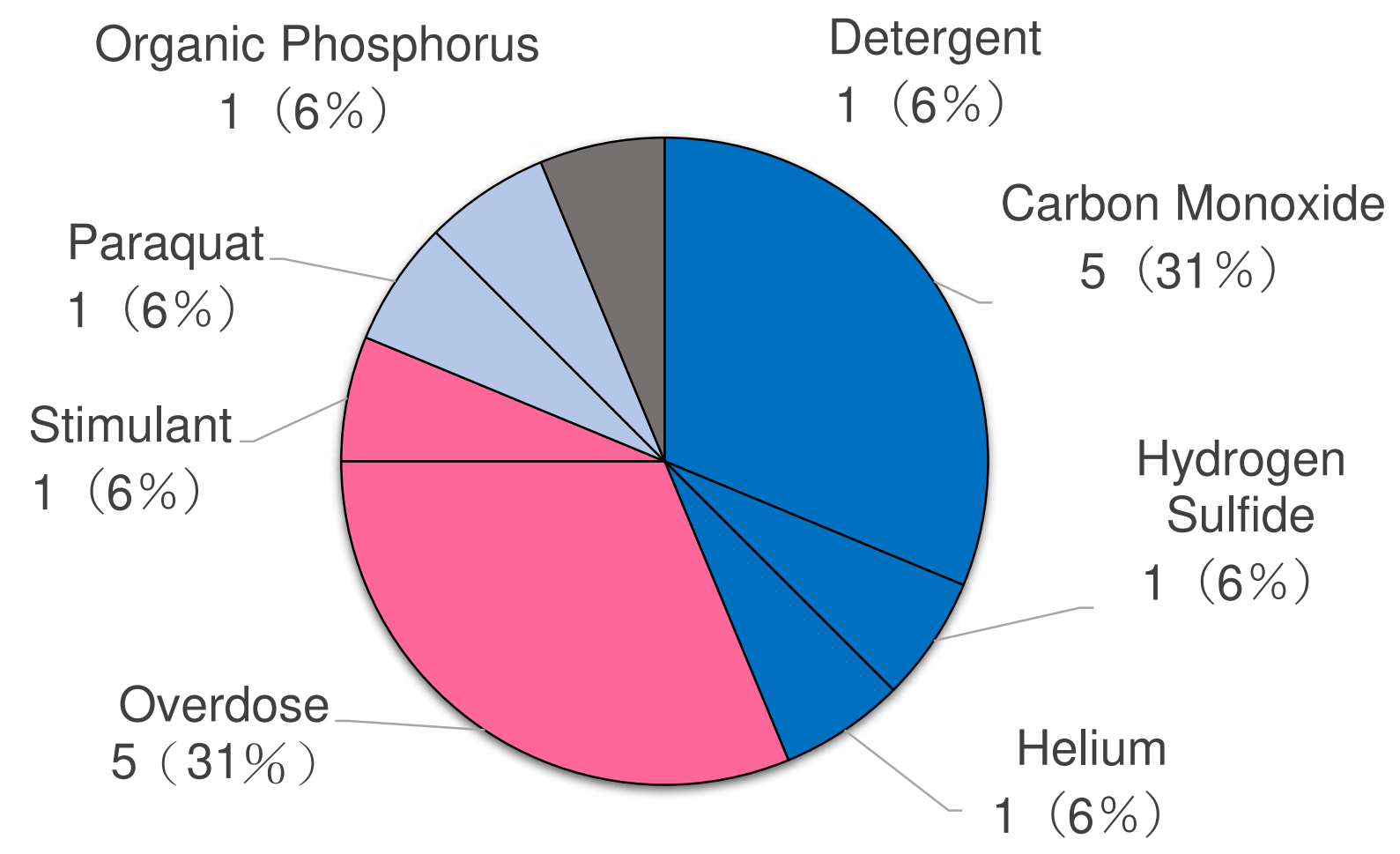

\section{3-3) Subsequent Hospitalization}

The average duration of subsequent hospitalization was 5 days.

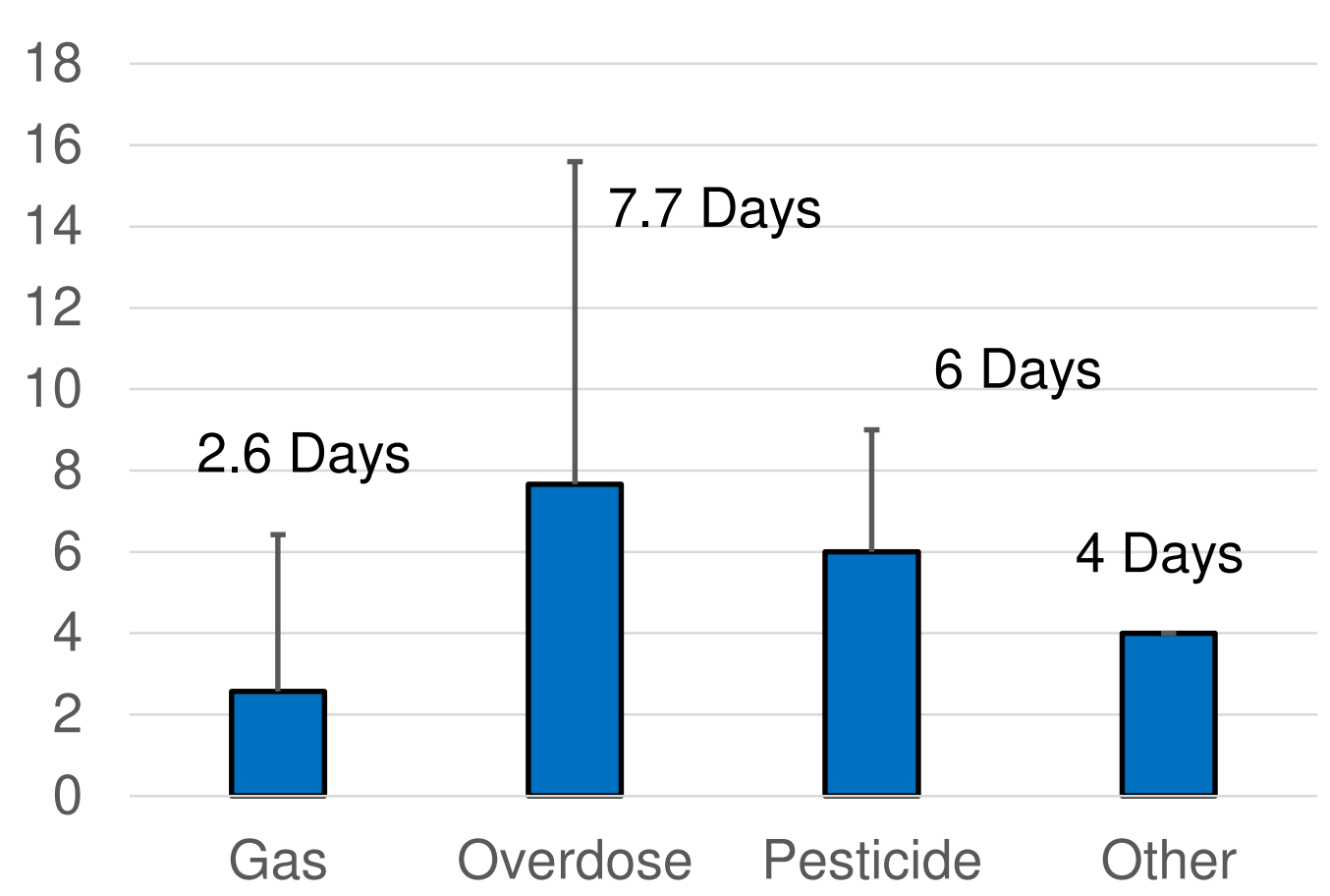

\section{3-4) History of Psychiatric Treatment}

12 cases consulted psychiatry, while 3 did not and 1 was unknown.

\section{3-5) Psychiatric Diagnosis}

Of 12 cases that consulted psychiatry, there were 5 of mood disorder, 2 of schizophrenia and neurotic disorder, 1 of personality disorder, and the 2 were unknown.

\section{Discussions}

【Sex and Agents】 Poisoning is a non-violent way, so female cases increased in the cases of poisoning.

【Subsequent Hospitalization】 Due to respiratory complications, we need to treat patients longer in cases of overdoses and pesticides.

【History of Psychiatric Treatment】 We assume that medications used for overdose were given in the clinics or hospitals. This means that we can prevent suicides in our daily clinical practice.

【Limits】We couldn't search previous attempts in our survey. We assume that patients attempted suicides repeatedly before its completion. 